Antonio Tucci. Professor of Sociology of Law at Università degli Studi di Salerno. His research interests focus on transformations of law in the global society; political spaces; processes of subjectivation and dynamics of inclusion/exclusion; dispositifs of power in the perspective of biopolitical paradigm.

Contact: a.tucci@unisa.it 


\section{CROSSING THE BORDERS OF GOVERNANCE}

\section{Antonio Tucci}

Università degli Studi di Salerno

Reception date $31^{\text {th }}$ January 2014; acceptance date $18^{\text {th }}$ March 2014. This article is developed within PRIN project (2010-2011) titled "Biopolitical governmentality", held at the Dipartimento di Scienze politiche, sociali e della comunicazione and Scienze giuridiche (Università degli Studi di Salerno).

\section{Abstract}

Governance is presented by undefined and confused areas that tend to expand in a more or less arbitrary way in the absence of stable and reliable normative standards. All this calls into question concepts and recompositive monolithic categories of modern political-legal rationality and in the first place sovereignty. At the same time the current neo-governmental structure does not stand as a technology of power, exclusionary or alternative to other rationalities, but rather it tends to bring out all the contradictions and ambiguities of the present time.

\section{Keywords}

Governmentality, sovereignty, political-legal subjectivations, borders

\section{Resumen}

La gobernanza es presentada por áreas confusas e indefinidas que tienden a expandirse de una manera más o menos arbitraria en ausencia de estándares normativos estables y confiables. Todo esto pone en cuestión conceptos y categorías monolíticas recompositivas de moderna racionalidad política-legal y en primer lugar de la soberanía. Al mismo tiempo, la estructura neogubernamental actual no se sostiene como una tecnología de poder excluyente o alternativa a otras racionalidades, sino que tiende a llevar a cabo todas las contradicciones y ambigüedades del tiempo presente. 


\section{Palabras clave}

Gubernamentalidad, soberanía, subjetivación de políticas legales, fronteras

\section{Government and governance, sovereignty and governmentality}

"Government is no longer an appropriate definition of the way in which populations and territories are organised and administered. In a world where the participation of business and civil society is increasingly the norm, the term governance better defines the process by which we collectively solve our problems and meet our society's needs, while government is rather the instrument we use"; the definition of governance provided by the OECD in 2001, echoes what we can read in the report drawn up in 1995 by the Commission on Global Governance. "Governance is the sum of the many ways individuals and institutions, public and private, manage their common affairs. It is a continuing process through which conflicting or diverse interests may be accommodated and cooperative action may be taken. It includes formal institutions and regimes empowered to enforce compliance, as well as informal arrangements that people and institutions either have agreed to or perceive to be in their interests."

Both terms, of course, refer to the transformation of government through new unprecedented ways of organization and administration of territories and populations; they place particular emphasis on the procedural and dynamic phenomenon to emphasize the distance from the traditional category of government, its forms, its fields and places which it however affects, and its institutions. The latter are, in any case, often reproduced assuming different modes of action, and-far from a definitive obsolescence-they effectively influence concrete power relations, so that "Governance is always effective in performing the function necessary to systematic persistence, else it is not conceived to exist" whilst "Government ... can be quite ineffective without being regarded as non-existent." ${ }^{2}$

1. Our Global Neighborhood: The Report of the Commission on Global Governance, 1995, http://www.gdrc.org/u-gov/global-neighbourhood/chapl.htm.

2. J. N. Rosenau, "Governance, Order, and Change in World Politics", in J.N. Rosenau, E.O. Czempiel (eds.), Governance without Government: Order and Change in World Politics, Cambridge University Press, Cambridge, 1992, pp. 4-5. 
Therefore, process, cooperative action, collective solution of conflicts and mediation seem to be the criteria for defining a logic of government that represents itself through practices (official documents talk about best practices and good governance ${ }^{3}$ ) inspired by freedom, equality, democracy, and ultimately a supposed (normative, and counter -factual) horizontality of powers in the field. ${ }^{4}$ This is a scenario that is more and more evoked in terms of lightness, softness and flexibility: ${ }^{5}$ it is true indeed that governance is presented by undefined and confused areas that tend to expand in a more or less arbitrary way in the absence of stable and reliable normative standards; it is, thus, true that it calls into question concepts and ricompositive monolithic categories of modern rationality, and in the first place sovereignty; but it is also and especially undeniable that the current neo-governmental structure (that appears to be well suited for governance practices $\left.^{6}\right)$, does not stand as a rational, exclusionary or alternative power to other rationalities, but rather it tends to bring out all the contradictions and ambiguities of the present time. More specifically, new prospects are developing and, although they highlight the absence of some rigid institutional frameworks, they underline now the centrality (often residual) of the State, or the imbalanced political-legal decision in favour of institutions and bodies lying beyond the public state sphere.

The tension between local and global leads us to rethink the centrality of the State: by re-reading Foucault, the history of the State and the long process of 'governmentalization' to which it has been subjected, ${ }^{7}$ we can assert that against the claim of unity of the sovereign power in the long history of the State, there have established widespread and ramified instances as opposed to the centre that undermine the supposed unity of the political and legal decision towards a process of pluralization of the legal system. A plurality of social issues that shows the theoretical inadequacy, rather than the concept

\footnotetext{
3. See the OECD Seminar proceedings on "Regulatory Management and Reform", Moscow, 19-20 November 2001, http:// www.oecd.org/gov/publicationsdocuments.

4. Cfr. S. Vaccaro, "Il dispositivo della Governance", in A. Palumbo, S. Vaccaro (eds.), Governance. Teorie, principi, modelli, pratiche nell'era globale, Mimesis, Milano-Udine, 2006.

5 M. R. Ferrarese, La governance tra politica e diritto, il Mulino, Bologna, 2010; J. S. Nye, Soft Power. The Means of Success in World Politics, PublicAffairs, New York, 2004, he talks about Soft Power as a criterion to exert power in international law as opposed to the coercive and repressive dominant views of Hard Power: «Hard and soft power are related because they are both aspects of ability to achieve one's purpose by affecting the behavior of others. The distinction between them is one of degree, both in the nature of the behavior and in tangibility of the resources. Command ... can rest on coercion or inducement. Co-optive power ... can rest on the attractiveness of one's culture and values or the ability to manipulate the agenda of political choices in a manner that makes others fail to express some preferences because they seem to be too unrealistic. ... Soft-power resources tend to be associated with the co-optive end of the spectrum of behaviour, whereas hard-power resources are usually associated with command behaviour», p. 7.

6. Cfr. L. Bazzicalupo, "Governamentalità: pratiche e concetti”, in Materiali per una storia della cultura giuridica, 2, 2013, pp. 371-394 and Editorial, in this volume.

7. M. Foucault, Sécurité, territoire, population. Cours au Collège de France. 1977-1978, Gallimard-Seuil, Paris, 2004.
} 
State-institution, of its identification with the paradigm of sovereignty that still serves as a criterion of significance in the discursive field of political and legal philosophy.

Undoubtedly, this is a particularly effective category when describing and rationalizing concrete moments of power: in fact, the State can define itself as sovereign whether it acts as the sole specific holder of prerogatives related to sovereignty, instrument of decisional legitimization as well as of coercive power that it exerts in a more or less exclusive way as a hierarchically superior political entity. However, if not exceptional, sovereignty is increasingly becoming a minority, especially under the current accomplished transformation of an interdependent and globalized world, and the hypertrophy of neoliberal capitalism. In this context, the complex and plural articulation of actors, of political and legal institutions which are ever more oriented towards widespread pluralistic forms of power can be read in the light of the governmental power technique. And it is exactly the opening to organizational and neo-governmental instances that may be useful to highlight indeed a continuous dialectic between the reductive moment, aimed to unity and concentration (sovereign logics) and centrifugal pluralistic moment, encompassing all pluralistic and multileveled forms of power in running (governmental rationality).

Governmentality is in fact an ambivalent and sometimes opaque instrument, but it allows us to rethink the theory and practice of the law, and the institution of the State as well as the supranational and inter-state institutions. It is necessary to bear in mind that the two paradigms (sovereignist and governmental) are not incompatible, although logically in contradiction and mutually exclusive: compatibility with different logics is, in fact, an essential and entirely new feature of the law that coexists with other logics. There is often a polarity between sovereign decisions and governmental negotiations that creates a messy, incoherent field, though not less real and concrete, of tensions and overlaps. ${ }^{8}$ It is about acquiring a critical-deconstructive approach to understand dynamics and processes that would otherwise escape any attempt for an appropriate representation of some traditionally effective categories which nowadays are no longer exhaustive. But with a warning in our opinion necessary: the attitude towards the sovereignist model cannot be that of those who take it as an inadequate and outdated model, but it does represent a specific device among all power devices, albeit the two logics are sharply opposed; one, sovereignty, is based upon the identification and legitimacy of the sovereign, and therefore it is completely internal to the political and legal discourse.

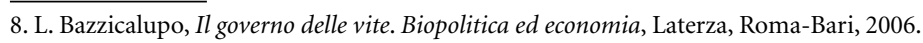


By contrast, the other, governmentality, focuses upon mechanisms of the social kind, which, through a series of persuasive, disciplinary, and bio-politics strategies, tends towards control and normalization. ${ }^{9}$ The specific purpose, therefore, becomes to "courtcircuiter ou d'éviter ce problème, central pour le droit, de la souveraineté et de l'obéissance des individus soumis à cette souveraineté, et de faire apparaître, à la place de la souveraineté et de l'obéissance, le problème de la domination et de l'assujettissement." 10

In this perspective, we can say that in modern self-representation softness alternates with hardness through an increasingly evident affirmation of modes of legal production characterized by soft law and lex mercatoria: law is becoming more inclusive, it tends to separate effectiveness from validity: in short, the law abandons its form, the clear distinction between normative phase and law enforcement phase. All this, however, takes place with obvious problems related in the first place to the democratic legitimacy of actors involved in the legal and political decision. These problems arise from the inability to think about new forms of production as projection on a global scale of the procedures and powers connected with them, which are typical of modern statehood: for instance, whether in a functioning national democracy a widespread participation and organization of interest groups flows directly into parliament and their laws implementation, a transnational and global nexus falls through inevitably. ${ }^{11}$

In other words, the framework proposed by the national model cannot be reproduced at the global level. The disjunction between popular involvement and multilateral cooperation, which takes decisions, involves conflicts of legitimacy and may lead to a paralysis of intergovernmental institutions: the balancing system, the impartial neutralising role played once by State institutions are missing out, and they cannot, of course, be automatically translated at a global level. ${ }^{12}$

This is certainly why Bevir argues that "a participatory democracy might ascribe a role in governance to a wide range of democratic groups in civil society as well as the State. Because we are dealing with fuzzy boundaries rather than sharp dichotomies, we should not be surprised that this vision finds some echoes in system governance,

9. «It is actually a perspective that draws attention to government as a heterogeneous field of thought and action-to the multiplicity of authorities, knowledges, strategies, and devices that have sought to govern conduct for specific ends", J. X. Inda, "Analytics of the Modern: An Introduction", in X. Inda (ed.), Anthropology of Modernity. Foucault, Governmentality, and Life Politics, Blackwell Publishing, Oxford, 2005 p. 7.

10. M. Foucault, Il faut défendre la société. Cours au Collège de France. 1976, Gallimard, Seuil, Paris, 2001, pp. 22-23.

11. R. O. Keohane-J. S. Nye, "Globalizzazione e Governance”, in A. Palumbo, S. Vaccaro (eds.), Governance. Teorie, principi, modelli, pratiche nell'era globale, pratiche nell'era globale, Mimesis, Milano-Udine, 2006, pp. 178-179.

12. About modern legal neutralization, A. Catania, Metamorfosi del diritto. Decisione e norma nell'età globale, Laterza, Roma-Bari, 2008, pp. 5-20. 
notably in devolution programmes and the use of partnerships between the public sector and the voluntary and private sectors", ${ }^{13}$ but this does not avoid, and does not exclude the assertion, often reactive, of fixed forms and rigid boundaries, which mark the global scenario, by reproducing regulation, control, and risk management devices to which we are increasingly submitted in governance systems. The activity of deconstruction involving the category of sovereignty is not accompanied, in fact, by the disappearance of borders; there is indeed a proliferation of borders, both material and symbolic, that ambivalently comes into being as an institution that separates and, at the same time, becomes a place of complex structured social and political relations, thus keeping together conflicts and mediations, divisions and connections, crossings and barriers together. "Borders regulate and structure the relations between capital, labour, law, subjects and political power even in instances where they are not lined by walls or other fortifications ... the regulatory functions and symbolic power of the borders test the barrier between sovereignty and more flexible forms of global governance." ${ }^{14}$ In other words, it is about putting into question the issue of territorial boundaries in modern spatiality, re-directing it to a concrete disaggregation of boundaries. ${ }^{15}$ It is no coincidence that today, upon a necessary redefinition of the concept of boundary, key parameter of the law and modern politics, have been focussing studies of great interest, which unhinge the traditional coincidence of the border with the images of wall and exclusion (correlative to national inclusion), to offer an image of a possible connection and intersection beyond the geopolitical boundaries tracked by international law and institutions to which it refers. ${ }^{16}$

\section{Bordering/De-bordering}

This ambivalence of boundaries - that goes beyond their interpretation as safety devices, through which we build techniques and strategies of political and geographical exclusion $^{17}$ - has been widely discussed in the Borders studies, which reveal how the

13. M. Bevir, "Democratic Governance: Systems and Radical Perspectives", in Public Administration Review, 3, 2006, p. 433. 14. S. Mezzadra, B. Neilson, Border as Method, Duke University Press, Durham and London, 2013, p. 8.

15. S. Sassen, A Sociology of Globalization, W. W. Norton \& Company, New York, 2007.

16. For studies on the classic paradigm of the border, see D. Newman, "The lines that continue to separate us: Borders in our borderless world", in Progress in Human Geography, 2, 2006, pp. 186-207.

17. About the border as a security device, see T. Basaran, "Security, Law, Borders: Spaces of Exclusion", in International Political Sociology", 2, 2008 and P. Zanini, Significati del confine. I limiti naturali, storici, mentali, Bruno Mondadori, Milano, 1997. Amongst the classical works by M. Davis, see at least, City of Quartz: Excavating the Future in Los Angeles, Verso, New York and London, 1990. 
contemporary world is witnessing processes of de-bordering that however, do not imply forms of erosion of the border, but its complex reorganization around different control priorities: strengthening of the borders, delimitation of spaces paradoxically overlapping with their own crisis. ${ }^{18}$ Wendy Brown, for instance, moves right from this double track where the global phenomena extricate themselves: "What we have come to call a globalized world harbors fundamental tensions between opening and barricading, fusion and partition, erasure and reinscription. These tensions materialize as increasingly liberalized borders, on the one hand, and the devolution of unprecedented funds, energies, and technologies to border fortification, on the other." ${ }^{19}$

In this way walls, by confirming a typical logic of governance, characterize themselves as devices to guarantee, alongside with freedom and security, risk management security policies, which often result into forms of national identity protectionism thereby confirming a state sovereignty that in each case is able to resist to change. Indeed, it is precisely through the construction of walls, the definition of marked boundaries, which the State "may look like hypersovereignty, but is actually often compensating for its loss. Lacking sovereign supremacy and majesty, yet invoking sovereign prerogative and guile, post-sovereign States become peculiar new kinds of international actors." ${ }^{20}$

It is quite interesting to note that when it comes to rethinking contemporary political-legal spatiality, Saskia Sassen defines the border as a productive place of sense, a sign by which we can delineate processes of localization and delocalisation of the new global dynamics and she argues that we are witnessing the creation of specific boundaries to contain and regulate emerging, often strategic flows which violate the traditional national boundaries, as in the case of the new regimes of international agreements and organizations (NAFTA, GATT, WTO) that promote circulation of highly skilled professionals whose movements are governed by a law that goes beyond the specific migration regimes of States, or even, as in the case of the economic position of a site in a global network of "boundaries", for which reason global economy appears as consisting of a series of specialized or partial circuits, as well as economic, multiple often overlapping spaces, precisely where the demarcation lines are becoming flexible, ambivalent, but never disappear despite the pressures of governance. ${ }^{21}$

\footnotetext{
18. P. Andreas, "Redrawing the Line. Borders and Security in the Twenty-first Century", in International Security, 2, 2003, pp. 78-111.

19. W. Brown, Walled State, Waning Sovereignty, Zone Books, New York, 2010, pp. 9-10.

20. Ibid., p. 59.

21. S. Sassen, A Sociology of Globalization, pp. 217-221.
} 
We can assert that border - one of the theoretical constructs of the legal and political modernity, as it sets the criteria of validity and effectiveness in a self-organizing meaningful legal system - is only apparently getting void or waning. Reality and concreteness of the national, international and transactional space draw boundaries which are crossing over the old still robust borders, yet they remain a pivotal dimension of governmentality that becomes in some way more evident in the global and seemingly unlimited range of its target. ${ }^{22}$ The myth and ideology that had been built around the country and the border, using the concept of an exclusive and excluding sovereignty, is surely declining as it stands as an artificial political mapping, and while is still there, it obviously cannot alone explain the meaning of power relations in the new forms of "zoning" and the new criteria of separation and delimitation of populations.

Even Sassen looks at territoriality - along with authority and rights - as a constitutive feature of the definition of the political and legal system. Law and politics, of course, in the global assemblages assume new configurations in presence of an incalculable variety of spatial-temporal characteristics - and therefore irreducible to system. Central categories to legal and political tradition, rather than being dismissed are challenged in the full sense of their meanings and relocated into in-formal synthesis of continuity and interruptions between national and global, universal and particular, between mobility and stability. Only incidentally, the concept of "assemblage" adopted by Sassen refers to specific national and global components that are assembled into new types of institutionalised entities; these are neither national nor global and manifest a variety of spatial-temporal features: the spatiality/temporality dimension of globalisation contains itself dynamics of mobility and fixity. ${ }^{23}$ In other words, those assemblages, in a ceaseless dialectic deprived of synthesis, presuppose and, at the same time, imply further disassembling through a series of "specific" and "complex" interactions. This oscillating movement calls into question the issue of territorial boundaries of modern spatiality in the direction of a concrete disaggregation of the border, which implies the need for a redefinition of the concept and of its coincidence with the image of the wall and exclusion.

The key concept of denationalization ${ }^{24}$ opens up to dynamic relations between national and global level, highlighting incomplete, imperfect, provisional, reviewable

22. J. Ferguson-A. Gupta, "Spatialing States: Toward an Etnography of Neoliberal Governmentality”, in J. X. Inda (ed.), Anthropology of Modernity, in which authors develop the idea of "an emerging system of transnational governmentality", p. 115.

23. S. Sassen, Territory, Authority, Rights: From Medieval to Global Assemblages, Princeton University Press, Princeton, 2006, pp. 406-414.

24. S. Sassen, “Denationalization or globalization?”, in Review of International Political Economy, 1, 2003, pp. 1-22. 
forms of confined and differentiated spaces; they do not coincide, or rarely they do, with the ancient geo-political partition. The global assemblages seem, therefore, to confirm the dominant rationality: territory is a legal space that is no longer organized in a pyramidal way but it has been inserted into a generally horizontal reticular organization, though persistently unequal and asymmetrical. As a result, these sociological-juridical investigations, while not denying the epochal even radical changes, do challenge any depictions of the State as "withering" or "retreating". For instance, the persistence of the State is evident in jurist Francesco Galgano's statements; he argues that "It is true that the political initiative of the States has given rise to the well known worldwide economy government organizations, such as the International Monetary Fund, the World Trade Organization, the World Bank Group, the World Health Organization and many others. Owing to these entities, according to a recurring formula, States shall cease to be uti singuli sovereign, in order to remain uti soci sovereign. However, it is equally true that these organizations, the so-called Governmental Organisations, are no longer able to operate as true and effective supranational organizations; rather, they have proved to perform as means for implementing policies centered by States from time to time». ${ }^{25}$

\section{An adapting law}

Following what it has been reasoned so far, we can argue that in the processes of global governance traditional universal categories place themselves in some sort of continuity/ discontinuity in contrast to the previous structures. Universals become concrete if you will, by abandoning the status of transcendence and pure logical statement, to be defined by actual practices of power relations. They therefore must endure relevant semantics twisting since they survive, taking on new outfits, the same contexts that had produced them. Forms do change, or rather, they adapt to new contexts which with great difficulties deal with the issue of order, unity, certainty and predictability: essential features of the formalistic sovereignist tradition centered on the repressive nature of the law.

Everything dissolves into a series of representations that are generated by the multiplicity of facets through which we can understand the otherwise unintelligible network of governance, thus revealing the impossibility of representing a complex and articulated reality solely by pre-established forms. It is therefore required a change of perspective that

25. F. Galgano, La globalizzazione nello specchio del diritto, Il Mulino, Bologna, 2005, p. 85. 
enables us to rethink the whole concept in the first place and the relation between law/ norm, and normativity/normalization. The form that modern constructivism represented as defined and coherent, but primarily transcending the empirical reality it was supposed to order takes the form of the mode-of-life, and becomes flexible and adherent to the contexts from which it emerges and to which it adapts, changing and adjusting them in turn.

This complexity of forms drives the political-legal theory to question whether or not decision-making processes can become immanent; this has more and more to do with the pluralisation and heterogeneity of the power centers, and the issue about order and security increasingly experienced in an dramatized way, and consequently, the problem of the use of force: issues which can be summarized into an obvious emergency of the factual and practical moment of the law. A vision of a world governed by a network of bordless relations and struggle would be too easy and irenic: it is important to recognize that the ability to cross governmental boundaries and create new ones finds moments of interruption and dispute - or even concrete conflict - where an undeniable presence of sovereign powers does exist, exercising coercion on migration flows and preventing their movement, or otherwise allowing the same conflict to be resolved legally. That conceptual claim of sovereignty to consider the political unity as a condition of possibility of the law is no longer maintainable: governmentality produces through its action movable zones of unity and coherence which can generate rules, though through a material and concrete, as well as temporary negotiation of the forces. The denationalized and transnational character of the economy, culture, politics, and therefore of social powers, on the other hand shows that there still are phenomena which the sovereign scheme allows us to identify, thereby confirming the principle of compatibility of rationalities.

It is about an overlap - a circle of "sovereignty-discipline-government" - that leads Aihwa Ong, in a work of critical deconstruction of sovereignty, to use what in the traditional lexicon would be an oxymoron: "graduated sovereignty".

Due to global capitalism - following vectors originating from external bodies of the State, but compromised with them - the national space, far from any final waning is re-articulated at multiple levels that are intertwined in a way that is neither hierarchical nor pyramidal. A same sovereign space is divided into special zones (according to specific government technologies of zoning ${ }^{26}$ ) which redefine their boundaries leaving

26. A. Ong, Neoliberalism as Exception: Mutations in Citizenship and Sovereignty, Duke University Press, Durham-London, 2006, in particular pp. 75-120; see also A. Ong, Flexible Citizenship: the Cultural Logic of Transnationality, Duke University Press, Durham-London, 1999. 
them porous, flexible, but still separated and regulated differently, thereby drawing an unprecedented mode of both sovereignty and citizenship. The logics reshaping different zones are numerous, from ethnicity and gender to the more often prevailing of profit: access to labor market, taxation systems, health and safety standards, industrial relations, environmental policy, driven by the logic of the market, do vary adapting to contexts. The coordination of policies and regulatory actions with their interests differently organized from time to time leads to a fragmentation of the national space in non-contiguous areas, promoting differentiated regulations about populations. The effect that these assemblages produce locally will then reverberate globally: graduated sovereignties in fact do not respect boundaries, but may cross them arbitrarily, and erect new or even old ones, giving rise to transnational networks.

This is thus a new approach to sovereignty that starts by affirming practices of "reterritorialisation" according to legal rules and heterogeneous, seemingly incompatible, government techniques. So, control and regulation refer to practices and government techniques, in which there are strategies of resistance and counter-conduct, thus confirming the inclusive/selective nature of governmental rationality. Rather than in the West, this logic of course is better highlighted in the complex articulation of politicallegal constellations of the southern-eastern Asian countries where neo-liberalism presents itself in the guise of exception and exemption from full legality: a logic indeed that fits also to the more particular and partial, targeted, specific and no longer general abstract interventions in the western countries. Here, administrative controls, citizenship, territoriality - once coalesced in the sovereign state - are dismembered, bringing out real sovereignties by intersection.

In the twentieth century legal theory lexicon, this process can be translated as the legal-formal positivism crisis, the normative and legal system-based conceptions, with the consequent affirmation of institutionalist organizational government conceptions which undermine the theoretical construct that had underlined the classical institutionalist theories: a formalistic and sovereign simplification in fact - we now may argue with no hesitation - cannot be exhaustive of all the phenomena we are now facing: these come into being through an endless dialectic between a reductive moment for unity and concentration, and a centrifugal, pluralistic, aggregating participation and power management moment.

The same form of institution, full of positivity and practicality loses its etymological connotation that had characterized it as a regulatory device capable of steadily regulating social relationships through a set of norms, values, stable and unreflective practices. 
Institutions today - while still maintaining the concrete positivity of complex devices - take on an extraordinary flexibility and elasticity, thus supporting the rhythm of an unprecedented transformation. Institutions are to give up much of their normative and coercive force, increasingly showing their factual immanent genesis, as they lose that connotation once referred to the universal and general model about associates' behavior. This normative weakness, however, refers from a strictly legal standpoint to the not simple and never definitively solved question over the proliferation and pluralization of legal systems. One thing is for sure: such institutions testify the impossibility to confine the analysis to the nexus order/legal system and so, they undermine its traditional hierarchical pyramidal connotation. Normativity is as technical as formal, as factual as well as immanent, and once again it calls into question that governmental biopolitical attitude of self-regulation which originally was critically compared with the sovereign and abstract government, by opposing to it the need to be "less governed", of the laissez faire. Governmentality does not refer to government over lives; it is about governing lives, and therefore it corresponds to an incremental, productive logic which coexists with the repressive/sanctioning nature of modern law. ${ }^{27}$

Therefore, it is about modalities of the law which work in the name of that immanent and factual (horizontal) normativity, and highlight the connotation of the same standards in terms of power and practice, rather than in terms of obligations and sanctions, according to which the distinction between lawful and unlawful is remarkable. Participatory, so to speak, forms of law come into being; they express forms of agency which jettison normativity in the strict sense to unleash construction and decision-making processes from below.

Coercive practices, therefore, while persisting at nodal points where the same sovereignty still operates to control space and boundaries in the name of safety and security - give way to mediation and negotiation. ${ }^{28}$ Such a shift in accent of the general system does not put an end to those practices of resistance prompted by forms of self-government and self-regulation that substantiate neo-liberal freedom: on the one hand, resistances hardly ever manifest themselves in the classic and modern form of antagonism, which leads to the typically coercive and sanctioning nature of these reactions, and to a more precise identification of the contenders in the conflict. On the other, they bring about practices that interpret resistance in terms of subtraction to

27. L. Bazzicalupo, Biopolitica. Una mappa concettuale, Carocci, Roma, 2010.

28. From a different perspective, R. Ellickson, Order without Law: How Neighbours Settle Disputes, Harvard University Press, Cambridge (Mass.) and London, 1991, in which the Author puts in perspective, well beyond the arguments of this essay, the imbalanced role of the law in favor of people's attitude to mediation and private negotiation. 
governance arrangements; as some sort of power repositioning in the gaps left unfettered by the molar regulation as well as an attempt to elude the law.

Government techniques, in other words, do not rule out anyone in principle; rather they do include selectively according to criteria which may vary depending on the purposes for which the government action has been programmed. Obedience and good conduct are therefore, effects of subjectivation processes which can generate submission by subjectivising, addressing and steering their energies towards a compliant selfgovernment. The issue about rights and identities results into forms of aggregation of individuals into groups (or populations) that share similar governmental features, and potentially capable of self-government. Surely, these implications of forms of discipline and control together with techniques of promptness and development can generate even more resistance and therefore, they define individuals and groups through deviations and differences that they know how to practice. The persistence of citizenship forms but also identity takes up a strategic profile, as if they were consolidated instruments to achieve concrete specific purposes, devices to be used in the real negotiation and transaction. Rather than simply formally, subjects are thus defined in accordance with residual categories of modernity such as identity and citizenship, at the crossroad, the intersection and overlap of subjectivising techniques (particularly, legal-formal or, even ethnicity-identity-based ones) alongside with subordination. In this alternation, or rather, compatibility of forms of mediation and negotiation, resistance and counterconduct, lie subjectivation processes which go beyond and exploit the categories in which the sovereign paradigm has traditionally pigeonholed the subject (national, autonomous rights holder, subject, etc.) to place themselves in government strategies and struggle. Within these categories, subjects take on an ambivalent status, either as free or autonomous subjects, or they are submitted to dominant discursive practices which are modified and adapted to them time by time, according to their own particular forms of life.

It is thereby confirmed the relational, procedural, power-generative conception so central to Foucault's reflection that marks the coming away and repositioning from a purely top-down conception of power to a horizontal exception where individuals are both subject and vehicle of the same power: ${ }^{29}$ "the disciplinary apparatus produces subjects, but as a consequence of that production, it brings into discourse the conditions for subverting that apparatus itself." ${ }^{30}$ 
All this, however may inevitably result in defining inclusion as integration and assimilation to a formal and abstract subject: a democratic political actor, according to the criteria and rules of the Western democratic tradition where conflict and antagonism are absorbed by cosmopolitan democratic procedures. ${ }^{31}$

Conversely, it can be difficult to accept that the bastions of our democratic culture are subject to legal forms of bargaining, but one needs to be aware of this, perhaps by signaling the emerging risks. Therefore, we must first try to understand how the subject, rather than being and defining itself in some pre-established way in respect of policy, it is given and identifies itself with - it connotes itself as - a political subjectivity, while remaining immersed in the social through forms of concrete special, contingent agency: thus no longer the subject and its universal rights, but the person who, involved in political and social practices - as H. Arendt suggests - does claim these rights by herself and use them in some way. One needs, therefore, to look at the practices of citizenship, in terms of the "politics of the governed." 32 In other words, one must refer to concrete forms sub-political and intergovernmental - of resistance and mediation of those excluded or assimilated, by taking up alternative though complementary routes with respect to the dominant discourses of truth. An operation that is well evidenced, for instance, within a process aimed at "reformulating the question about colonialism", ${ }^{33}$ by those who, in the light of the governmental technologies emphasize the constitutive heterogeneity of the global space as a temporary and unstable product of a complex process, with the obvious consequence of the emergence of stories and subjectivities "other" than the homogeneous and complying story of the nation state, seen that "if with sovereignty, the relation between ruler and ruled is such that power reaches out like an extension of the arm of the prince himself, announcing itself periodically with unambiguous ceremony, with government, governor and governed are thrown into a new and different relation, one that is the product not merely of the expanded capacity of the State apparatus but of the emergence of a new field for producing effects of power - the new, self-regulating field of the social": ${ }^{34}$ an area which is affected by individuals, groups and heterogeneous populations, in no way related to the uniform homogeneous forms and limits that characterized the system of the Rule of Law, of rights and citizenship.

31. In this sense, S. Benhabib, The Rights of Others, Cambridge University Press, Cambridge, 2004 and see, Another Cosmopolitanism: Hospitality, Sovereignty, and Democratic Iterations, Oxford University Press, Oxford, 2006.

32. P. Chatterjee, The Politics of the Governed: Reflections on Popular Politics in Most of the World, Columbia University Press, New York, 2004.

33. D. Scott, Colonial Governmentality, in J. X. Inda (ed.), Anthropology of Modernity, p. 23.

34. Ibid., pp. 33-34. 